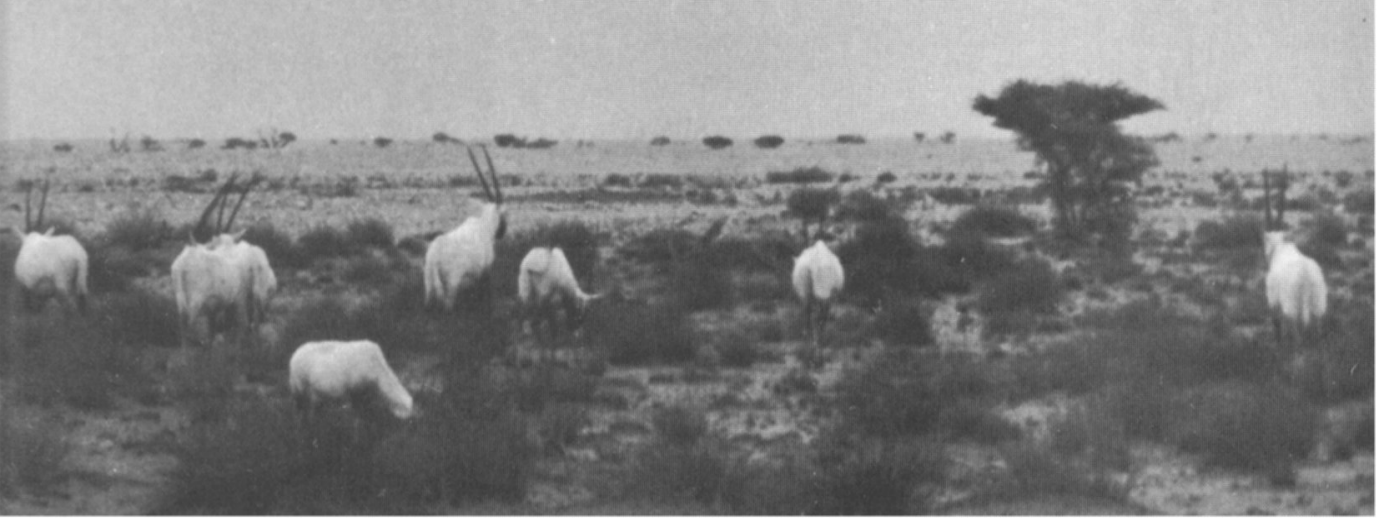

\title{
Arabian Oryx Return to the Wild
}

On 31 January this year ten captivebred Arabian ory $\mathrm{x}$ were released into the wild in the Jiddat-al-Harasis in Oman - a red-letter day for the species which is thought to be extinct in the wild, for the zoos which have bred the animals, for the people of Oman, and for conservationists everywhere, but especially for ffPS, the Society that initiated and organized Operation Oryx. The three wild oryx captured in 1962 in the FPS expedition, supported by WWF, became the nucleus of the World Herd that was built up in Phoenix and San Diego Zoos in the USA, from which the animals released in Oman were assembled: four males and four females, together with a yearling and a calf born in Oman on the White Oryx Project of HM Sultan Qaboos bin Said.

The ten oryx were only released after careful observation by the Project Manager, Dr Mark Stanley Price, and the Bedu rangers of the Harasis tribe who will guard the oryx, showed that they had developed a stable social structure, each animal having a fixed position in the hierarchy, and that they moved as a group. Last November five of the herd were immobilized by Dr Michael Woodford, veterinarian on Operation Oryx, and radio-collared, two of the collars being solar-powered, so that their movements could be followed.

The release area had had no significant rain for six years, so there was little grazing, and supplementary feeding had to continue. But three weeks later torrential rain produced floods in the desert just as the Duke of Edinburgh, President of WWF, arrived gum boots for the Duke but new grass for the oryx, which soon lost interest in hay and lucerne. In March a calf was born to the mother of the calf in the herd, and unlike the first, which had had to be hand-reared, was suckling when a few hours old.

By the end of March the herd was moving freely in abundant grass in a $60-\mathrm{sq}-\mathrm{km}$ area. All were in good condition, and the enthusiastic Harasis say that the white oryx herd now behaves like the ory $x$ of old.

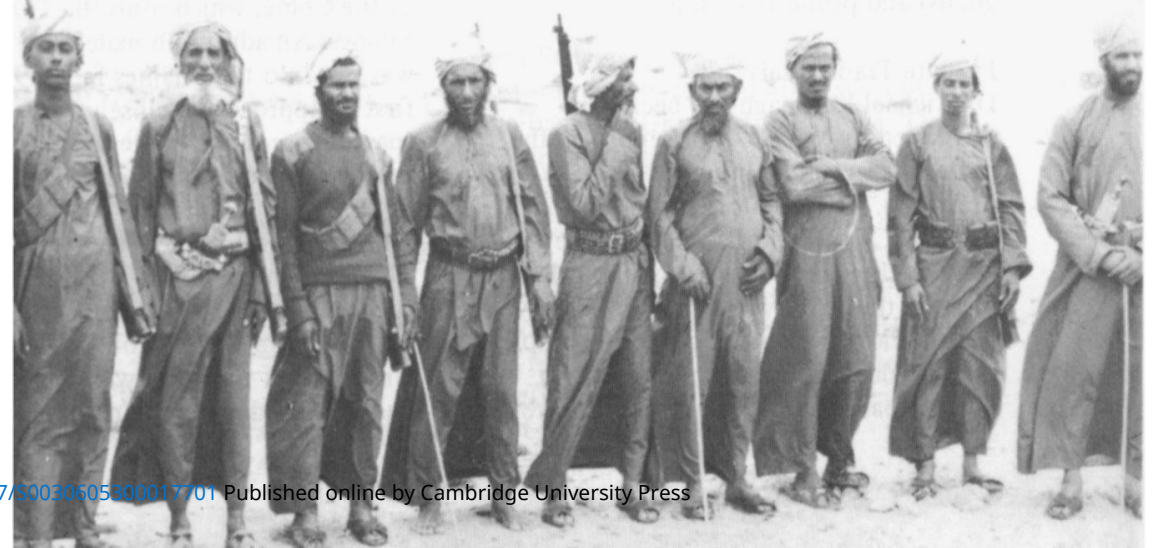

